\title{
MicroRNA-320 regulates autophagy in retinoblastoma by targeting hypoxia inducible factor-1 $\alpha$
}

\author{
YONG LIANG, XI CHEN and ZHU LIANG \\ Department of Ophthalmology, The Ninth People's Hospital of Chongqing, Chongqing 400700, P.R. China
}

Received August 29, 2016; Accepted May 11, 2017

DOI: $10.3892 /$ etm.2017.4779

\begin{abstract}
Retinoblastoma (RB) is the most common malignancy in children. Due to refractory mechanisms of chemoresistance and the toxicity of chemotherapies, novel therapies for RB treatment are urgently required. MicroRNA-320 (miR-320) is believed to be associated with the tumorigenesis of $\mathrm{RB}$, although the mechanism remains unclear. Considering the hypoxic intratumoral region, the roles of miR-320 and hypoxia inducible factor- $1 \alpha$ (HIF-1 $\alpha$ ) in the regulation of autophagy were investigated in 30 human RB samples and WERI-RB1 cells. The results demonstrated that HIF-1 $\alpha$ was the downstream target of miR-320, and decreased miRNA-320 or HIF-1 $\alpha$ lead to the inhibition of autophagy in WERI-RB1 cells. Compared with WERI-RB1 cells that were not transfected, silenced HIF-1 $\alpha$ caused a 1.41-fold increase $(\mathrm{P}<0.01)$ in p62, a 2.71-fold decrease of Beclin1, and inhibited miRNA-320. Silenced HIF-1 $\alpha$ also resulted in 7.29- and 7.43-fold increases in phosphorylated-mechanistic target of rapamycin (mTOR) and mTOR, respectively. In conclusion, the present results suggest that miRNA-320 may regulate the development of autophagy by targeting HIF- $1 \alpha$ and autophagy-related proteins in RB under hypoxic conditions.
\end{abstract}

\section{Introduction}

Retinoblastoma (RB), which is usually caused by defective $R B 1$, is the most common type of malignant intraocular cancer that typically occurs in childhood (1). The incidence of RB is relatively constant with one case for every 15,000-20,000 live births or approximately 9,000 new cases worldwide annually (2). Five-year-old children are the most predisposed population to RB (3). Clinical presentations of RB consist of leukocoria, strabismus, nystagmus, red eye, and loss of binocularity depending on the tumor location (4). Currently,

Correspondence to: Professor Yong Liang, Department of Ophthalmology, The Ninth People's Hospital of Chongqing, 69 Jialing Village, Chongqing 400700, P.R. China

E-mail: liangyong53@126.com

Key words: microRNA-320, retinoblastoma, hypoxia inducible factor-1 $\alpha$, autophagy, Beclin-1, p62, mechanistic target of rapamycin globe-salvaging strategies include laser photocoagulation, cryotherapy, thermotherapy, intravenous chemoreduction, intra-arterial chemotherapy, and external beam radiotherapy as well as enucleation in the clinical management of RB (5). Given the disappointing refractory mechanisms of chemoresistance and the toxicity of chemotherapies, novel therapies are urgently required for $\mathrm{RB}$ treatment.

MicroRNA (miRNA or miR) are a group of specific small ( 22 nucleotides), non-coding, single-stranded ribonucleic acids that participate in cellular proliferation, growth, death, differentiation, apoptosis and metabolism as inhibitors of target mRNA (6). Various miRNA have been implicated in the invasion, metastasis, and maturation of several types of cancer, including RB (7-10). miR-320 has been demonstrated to be involved in various types of cancer, including colorectal cancer (11), non-small cell lung cancer (12), cervical cancer (13), and oral cancer (14). In a previous miRNA microarray analysis, miR-320 was identified to be associated with the tumorigenesis of $\mathrm{RB}$ for the first time, indicating that miR-320 has a role in the regulation of RB development (15). However, the underlying mechanisms of miR-320 remained unclear in RB.

Hypoxia, which refers to oxygen deficiency, is a characteristic feature in interior tumors in which metabolism and proliferation are slow and readily lead to chemotherapy resistance (16). Hypoxia regulates various pathways, including the hypoxia inducible factor- $1 \alpha$ (HIF-1 $\alpha$ ) pathway. HIF- $1 \alpha$ is an oxygen-dependent subunit of HIF-1, which has another constitutively expressed (HIF-1 $\beta$ subunit); HIF- $1 \alpha$ and HIF-1 $\beta$ are members of the basic helix-loop-helix-Per-ARNT-Sim (bHLH-PAS) protein family (17). In previous studies, deregulated HIF-1 $\alpha$ was observed in RB hypoxic regions (18), and HIF-1 $\alpha$ levels were associated with the survival and proliferation of RB cells (19). Therefore, we hypothesized that miR-320 may affect RB development by influencing HIF-1 $\alpha$ levels.

In the present study, the primary objective was to clarify the effect of miR-320 on autophagy and how this process is performed via HIF-1 $\alpha$ by analyzing both mRNA and protein expression levels of Beclin-1, p62, mechanistic target of rapamycin (mTOR) and phosphorylated (p)-mTOR in RB cells.

\section{Materials and methods}

$R B$ samples. Retinal tissues were collected from 30 patients with RB that had not undergone chemotherapy and radiotherapy 
prior to enucleation in the Department of Ophthalmology at The Ninth People's Hospital of Chongqing (Chongqing, China). The patients included 18 men and 12 women with the age range of 0.5-8.9 years (mean, 3.2). According to ICRB, the RB patients were divided into I phase (6 cases), II phase (13 cases) and III phase (11 cases). The adjacent healthy tissues were set as the control. Written informed consent was obtained from each patient. The experimental protocol was preapproved by the Medical Ethics Committee of The Ninth People's Hospital of Chongqing.

Cell culture and grouping. The human RB cell line (WERI-RB1) was purchased from the Cell Bank of the Chinese Academy of Sciences (Shanghai, China), and cultured to $70 \%$ confluence in RPMI-1640 (Gibco; Thermo Fisher Scientific, Inc., Waltham, MA, USA) supplemented with $10 \%$ fetal bovine serum (FBS; Hyclone, Logan, UT, USA), $100 \mathrm{U} / \mathrm{ml}$ penicillin, and $100 \mathrm{mg} / \mathrm{ml}$ streptomycin at $37^{\circ} \mathrm{C}$ under normoxic conditions of $100 \%$ humidity, $95 \%$ air and $5 \% \mathrm{CO}_{2}$ or under hypoxic conditions of $2 \% \mathrm{O}_{2}, 93 \% \mathrm{~N}_{2}$ and $5 \% \mathrm{CO}_{2}$. Cells were divided into four groups as determined by the following conditions: Normoxia, hypoxia, hypoxia + miRNA-320 inhibitor, and hypoxia + HIF-1 $\alpha$ siRNA.

Reverse transcription-quantitative polymerase chain reaction $(R T-q P C R)$. Total RNA was isolated from WERI-RB1 cells using TRIzol reagent (Invitrogen; Thermo Fisher Scientific, Inc.) according to the manufacturer's instructions. RNA purity was assessed at OD260/OD280 (values, 1.7-2.0). RNA $(1 \mu \mathrm{g})$ was reverse transcribed into cDNA and amplified via qPCR using a Rotor-Gene 3000 Real-Time PCR System (Corbett Robotics, Brisbane, Australia) and SYBR-Green reporter dye (Invitrogen; Thermo Fisher Scientific, Inc.). GAPDH was used as a reference gene. Primers were synthesized by Sangon (Shanghai, China) and the sequences were as follows: miR-320, 5'-AAAAGCTGGGTTGAGAGGGCGA-3'; HIF-1 $\alpha$, forward 5'-GAAACCACCTATCAGCTGC-3' and reverse 5'-AGTGTACCCTAACTAGCCGAGGAA-3'; and GAPDH, forward 5'-AGCCACATCGCTCAGACA-3' and reverse 5'-TGGACTCCACGACGTACT-3'. Thermal cycling during the PCR amplification protocol was performed as follows: $95^{\circ} \mathrm{C}$ for $5 \mathrm{~min}$, followed by 40 cycles of $95^{\circ} \mathrm{C}$ for $30 \mathrm{sec}$, $58^{\circ} \mathrm{C}$ for $30 \mathrm{sec}$, and $72^{\circ} \mathrm{C}$ for $30 \mathrm{sec}$. Relative expression was analyzed using the $2^{-\Delta \Delta \mathrm{Cq}}$ method, as previously described (20).

miRNA-320 inhibitor and HIF-1 $\alpha$ siRNA treatment. miRNA-320 inhibitor and HIF-1 $\alpha$ siRNA were synthesized by GenePharma, Co., Ltd., (Shanghai, China). WERI-RB1 cells were transfected with miRNA-320 inhibitor $(30 \mathrm{nM})$ using Lipofectamine ${ }^{\circledR} 3000$ transfection reagent for $48 \mathrm{~h}$ and HIF-1 $\alpha$ siRNA (100 nM) using Metafectene reagent (Biontex, München, Germany) for $5 \mathrm{~h}$, according to the manufacturers' instructions.

Western blotting. Proteins (HIF-1 $\alpha$, Beclin1 and p62) were extracted from WERI-RB1 cells using an EpiQuik Total Histone Extraction Kit (Epigentek, Farmingdale, NY, USA). Protein contentions were determined using a BCA Protein Quantification kit (Vazyma, Nanjing, China) according to the manufacturer's instructions. Equal amounts of protein $(50 \mu \mathrm{g})$ were separated by $12 \%$ SDS-PAGE and transferred to polyvinylidene difluoride membrane (EMD Millipore, Billerica, MA, USA). Subsequently, the membranes were blocked with $5 \%$ skimmed-milk powder in TBST buffer $(\mathrm{pH} 7.5 ; 10 \mathrm{mM}$ Tris- $\mathrm{HCl}, 150 \mathrm{mM} \mathrm{NaCl}$ and $0.05 \%$ Tween-20) for $2 \mathrm{~h}$ at room temperature. Target proteins were incubated with mouse anti-human monoclonal antibodies against HIF-1 $\alpha$, Beclin1, p62, mTOR and p-mTOR (all 1:100; cat. nos. ab62557, ab56416, ab113642, ab2732 and ab109268, respectively; Abcam, Cambridge, UK) and human anti-GAPDH monoclonal antibody (1:1,000; cat. no. AG019; Beyotime Institute of Biotechnology, Beijing, China) overnight at $4^{\circ} \mathrm{C}$. Followed washing with TBST three times, the membrane was incubated with secondary anti-rabbit antibody conjugated with horseradish peroxidase (1:2,000; cat. no. AG019; Beyotime Institute of Biotechnology) for $30 \mathrm{~min}$ and detected by enhanced chemiluminescence (Beyotime Institute of Biotechnology). Gray values of the target proteins were quantified using Quantity One v4.62 software (Bio-Rad Laboratories, Inc., Hercules, CA, USA).

Luciferase reporter assay. WERI-RB1 cell groups that underwent transfection were as follows: miR-320 inhibitor + pMIR-HIF- $1 \alpha$-Wt; miR-320 NC+pMIR-HIF- $1 \alpha-W t$; miR-320 inhibitor + pMIR-HIF-1 $\alpha$-Mut; and miR-320 $\mathrm{NC}+$ pMIR-HIF-1 $\alpha$-Mut, in which pMIR-HIF-1 $\alpha$-Wt and pMIR-HIF-1 $\alpha$-Mut were synthesized by Ribobio Co., Ltd., (Guangzhou, China). WERI-RB1 cells were lysed in passive lysing buffer, and Firefly and Renilla luciferase activities were detected via a commercial Dual-Luciferase assay kit (E1910; Promega Corp, Madison, WI, USA) according to the manufacturer's instructions. Relative fluorescence units (RFUs) were calculated as a ratio of Firefly luciferase to Renilla luciferase signal intensity.

Fluorescence microscopy. After $48 \mathrm{~h}$ of cultivation, WERI-RB1 cells transfected with LC3 were seeded on glass coverslips, fixed with $4 \%$ pre-cooled paraformaldehyde for 10 min, rinsed with sterile PBS three times, and mixed with serum supplemented with $0.1 \%$ Triton X-100. Subsequently, the cells were incubated with primary LC3 polyclonal antibody (1:100; cat. no. ab48394; Abcam) overnight at $4^{\circ} \mathrm{C}$, rinsed with PBS, and cultured with a secondary antibody (1:200; cat. no. AG019; Beyotime Institute of Biotechnology) for $1 \mathrm{~h}$ at room temperature. Incubated cells were mixed with DAPI for nuclear staining and quantified using ImageJ v1.84 software (National Institutes of Health, Bethesda, MA, USA).

Statistical analysis. Experiments were performed in triplicate on three independent occasions. Data were presented as the mean \pm standard deviation and analyzed using a two-tailed Student's t-test between two groups. Statistical analyses were conducted by SPSS 17.0 (SPSS, Inc., Chicago, IL, USA). $\mathrm{P}<0.05$ was considered to indicate a statistically significant difference.

\section{Results}

Expression of miR-320 in RB tissues. In comparison with a previous report $(15)$, we expanded RB samples $(n=30)$ to 


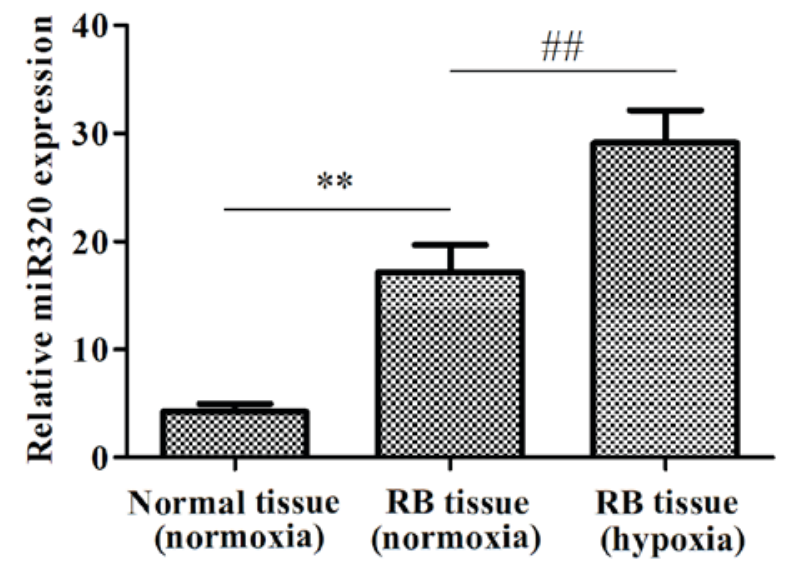

Figure 1. Relative expression levels of miR-320 were analyzed by reverse transcription-quantitative polymerase chain reaction in normal and $\mathrm{RB}$ tissues under normoxic and hypoxic conditions. GAPDH was used as a reference gene. ${ }^{* *} \mathrm{P}<0.01$ vs. the normal tissue under normoxic conditions; ${ }^{\# \#} \mathrm{P}<0.01$ vs. $\mathrm{RB}$ tissue under normoxic conditions. $\mathrm{RB}$, retinoblastoma.

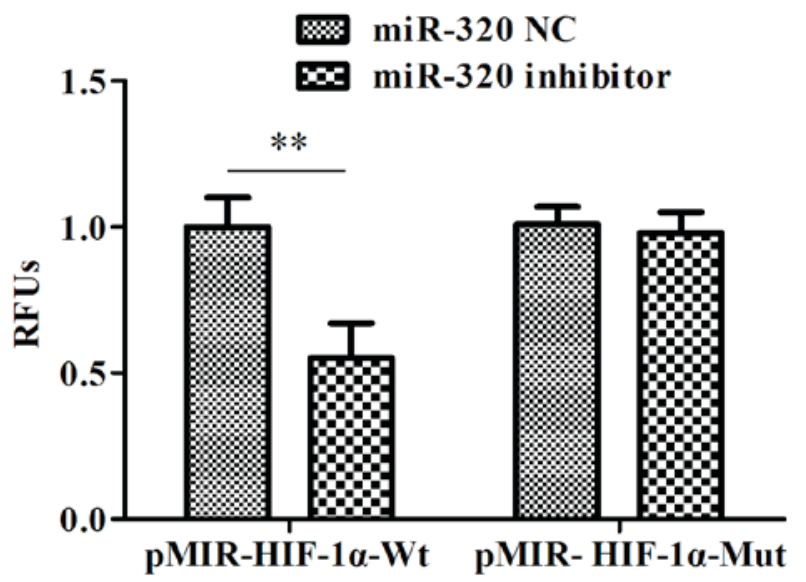

Figure 2. RFUs were calculated to analyze the association between miR-320 and HIF-1 $\alpha$ via a luciferase reporter assay in WERI-RB1 cells. RB cells were respectively transfected with miR-320 inhibitor + pMIR-HIF-1 $\alpha-\mathrm{Wt}$, miR-320 NC + pMIR-HIF-1 $\alpha$-Wt, miR-320 inhibitor + pMIR-HIF-1 $\alpha$-Mut, and miR-320 NC + pMIR-HIF-1 $\alpha$-Mut. pMIR-HIF- $1 \alpha$-Wt was a vector containing wild HIF-1 $\alpha$ sequence. pMIR-HIF- $1 \alpha-$ Mut was a vector including mutated HIF-1 $\alpha$ sequence. ${ }^{* *} \mathrm{P}<0.01$ vs. RB cells transfected with miR-320 $\mathrm{NC}+$ pMIR-HIF-1 $\alpha$-Wt. RFUs, relative fluorescence units; RB, retinoblastoma; Mut, mutant; Wt, wild-type.

determine the expression of miR-320. As shown, the expression levels of miR-320 increased significantly in RB tissues ( $\mathrm{P}<0.01$; Fig. 1) when compared with adjacent normal tissue under normoxic conditions. Furthermore, the expression of miR-320 was significantly increased in hypoxic RB tissues when compared with normoxic RB tissues ( $\mathrm{P}<0.01$; Fig. 1).

Association between miR-320 with HIF-1 $\alpha$. Luciferase reporter assay was employed to analyze the association between miR-320 and HIF-1 $\alpha$. The results demonstrated that the RFUs decreased significantly in RB cells transfected with miR-320 inhibitor + pMIR-HIF- $1 \alpha$-Wt compared with the cells transfected with miR-320 NC + pMIR-HIF-1 $\alpha$-Wt $(\mathrm{P}<0.01$; Fig. 2). However, there was no difference in RFUs between the cells transfected with miR-320 NC + pMIR-HIF-1 $\alpha$-Mut and miR-320 inhibitor + pMIR-HIF-1 $\alpha$-Mut. Notably, mRNA
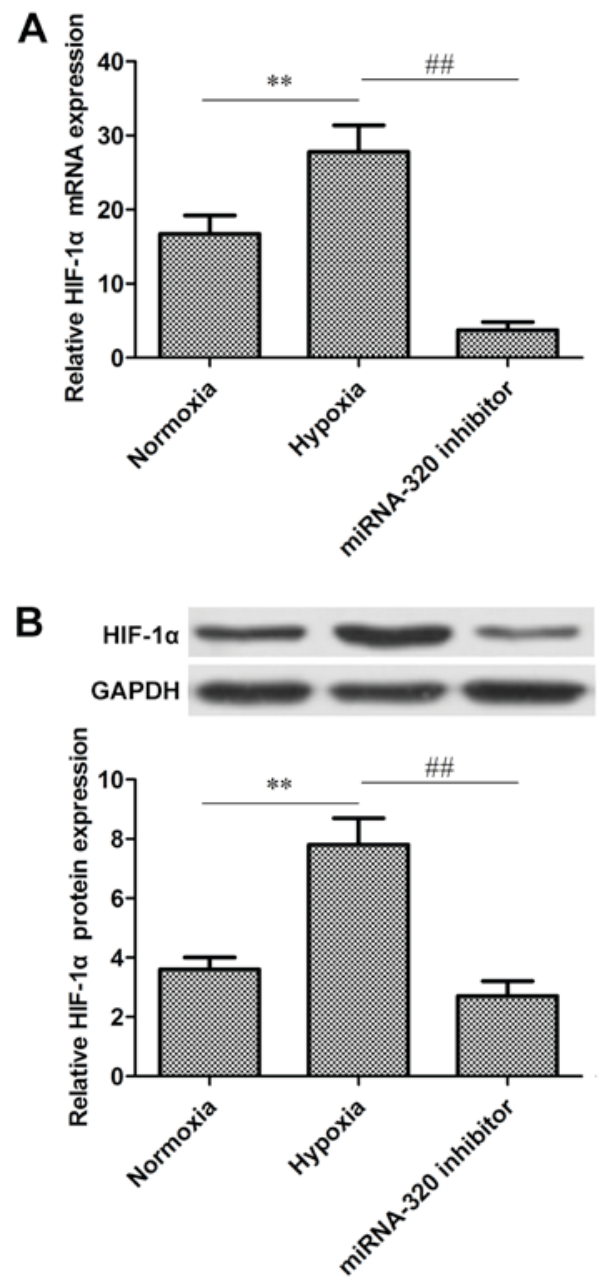

Figure 3. (A) Relative mRNA expression levels of HIF-1 $\alpha$ were analyzed by reverse transcription-quantitative polymerase chain reaction, and (B) representative images and relative protein levels of HIF-1 $\alpha$ were recorded by western blot and quantified by Quantity One v4.62 software in WERI-RB1 cells under normoxic conditions, hypoxic conditions and hypoxic conditions + miR-320 inhibitor. GAPDH was used as a reference gene and protein. ${ }^{* *} \mathrm{P}<0.01$ vs. $\mathrm{RB}$ cells under normoxic conditions; ${ }^{\# \#} \mathrm{P}<0.01$ vs. RB cells under hypoxic conditions. HIF-1 $\alpha$, hypoxia inducible factor- $1 \alpha$; $\mathrm{RB}$, retinoblastoma.

and protein expression levels of HIF-1 $\alpha$ increased significantly under hypoxic conditions when compared with normoxic conditions, whereas expression levels significantly decreased under hypoxia when miR-320 was inhibited $(\mathrm{P}<0.01$, Fig. 3A and $\mathrm{B}$, respectively).

LC3 puncta assay. Autophagy was investigated to illustrate the underlying mechanism of how miR-320 regulates RB development under hypoxia via targeting HIF-1 $\alpha$. It was demonstrated that the puncta quantity increased significantly under hypoxic conditions when compared with cells cultured under normoxic conditions, indicating that $\mathrm{LC} 3$ puncta accumulated in $\mathrm{RB}$ cells $(\mathrm{P}<0.01$; Figs. 4 and 5). By contrast, inhibited miR-320 and silenced HIF-1 $\alpha$ resulted in remarkable decrease of the puncta quantity, inferring LC3 puncta was removed from RB cells ( $\mathrm{P}<0.01$, Figs. 4 and 5).

Expression of autophagy-related proteins. Protein expression levels of p62, Beclin1, p-mTOR and mTOR were evaluated 


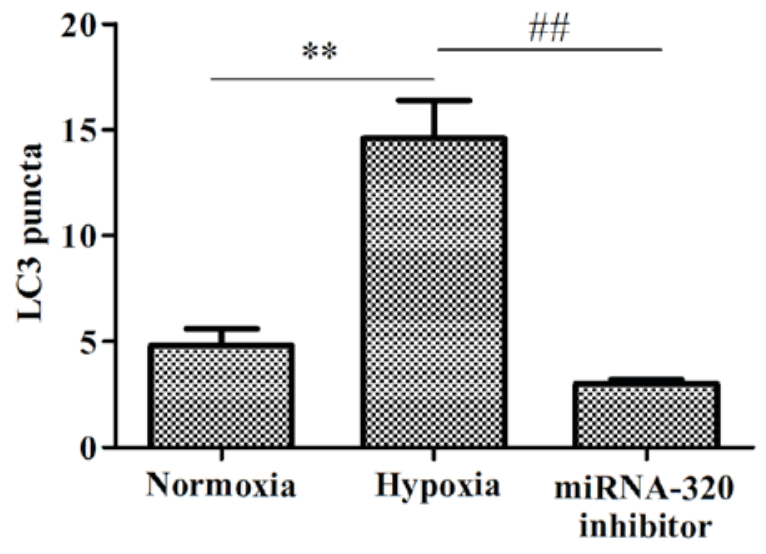

Figure 4. LC3 puncta was quantified by ImageJ to investigate autophagy in WERI-RB1 cells under normoxic conditions, hypoxic conditions and hypoxic conditions + miR-320 inhibitor. RB cells were incubated with LC3 polyclonal antibody and DAPI consecutively. ${ }^{* *} \mathrm{P}<0.01$ vs. RB cells under normoxic conditions; ${ }^{\#} \mathrm{P}<0.01$ vs. RB cells under hypoxic conditions. LC3, light chain 3; RB, retinoblastoma; DAPI, 4'6'-diamino-2-phenylindole dihydrochloride.

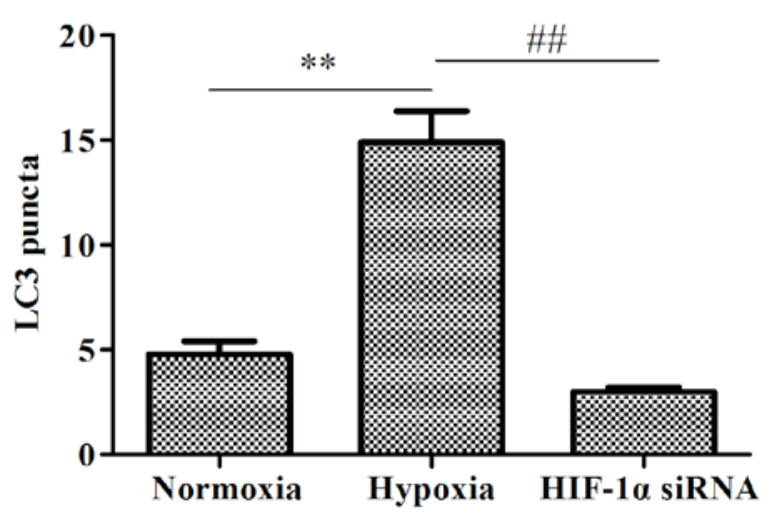

Figure 5. LC3 puncta was quantified by ImageJ to survey autophagy in WERI-RB1 cells under normoxic conditions, hypoxic conditions and hypoxic conditions + HIF-1 $\alpha$ siRNA. RB cells were incubated with LC3 polyclonal antibody and DAPI consecutively. ${ }^{* *} \mathrm{P}<0.01$, compared with RB cells under normoxic conditions; ${ }^{\# \#} \mathrm{P}<0.01$ vs. RB cells under hypoxic conditions. LC3, light chain 3; RB, retinoblastoma; DAPI, 4'6'-diamino-2-phenylindole dihydrochloride.

and their relative levels were quantified. As shown, the expression of p62 decreased by 3 -fold $(\mathrm{P}<0.01)$ under hypoxia compared with the cells cultured under normoxic conditions, and HIF- $1 \alpha$ silencing caused a 1.41 -fold increase in p62 $(\mathrm{P}<0.01)$ compared with the cells cultured under hypoxic conditions (Fig. 6A). Expression of Beclin1 increased by 2.21-fold $(\mathrm{P}<0.01)$ under hypoxic conditions when compared with the cells normoxic conditions, and HIF-1 $\alpha$ silencing caused a 2.71-fold decrease in Beclin1 $(\mathrm{P}<0.01)$, as compared with the cells cultured under hypoxic conditions (Fig. 6B). Furthermore, the expression levels of p-mTOR and mTOR were investigated and the ratio of $\mathrm{p}-\mathrm{mTOR} / \mathrm{mTOR}$ calculated. It was observed that $\mathrm{p}$-mTOR/mTOR decreased by 8.29 -fold under hypoxic conditions when compared with cells cultured under normoxic conditions $(\mathrm{P}<0.01)$; miR-320 inhibition and HIF-1 $\alpha$ silencing lead to 7.29 -fold $(\mathrm{P}<0.01)$ and 7.43 -fold increases $(\mathrm{P}<0.01)$ compared with the cells cultured under hypoxic conditions (Fig. 6C).
A

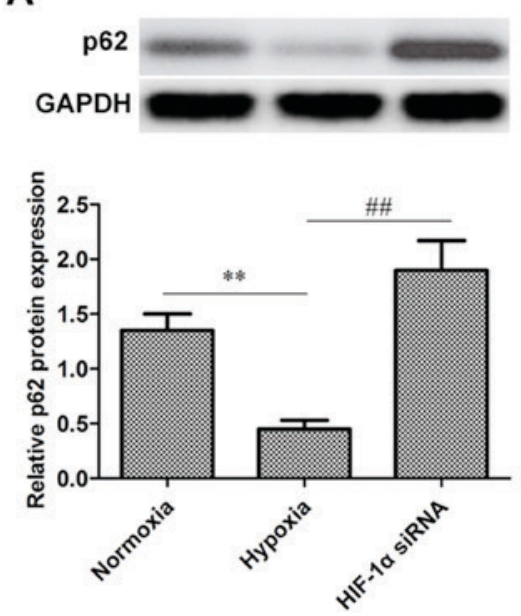

B
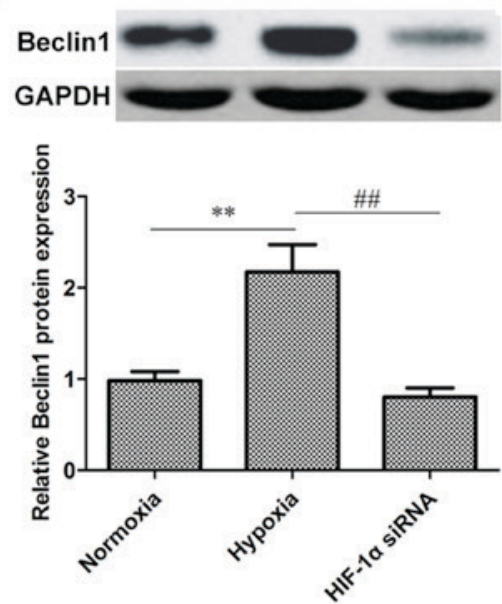

C
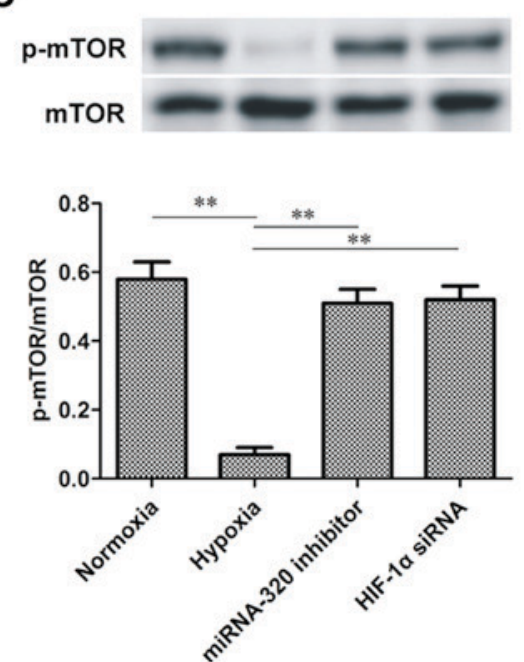

Figure 6. Representative images and relative protein expression levels of (A) p62 and (B) Beclin1 were assessed by western blotting and quantified by Quantity One v4.62 software in WERI-RB1 cells under normoxic conditions, hypoxic conditions and hypoxic conditions + HIF-1 $\alpha$ siRNA. (C) Representative images of p-mTOR and mTOR following western blotting, and the relative ratios of $\mathrm{p}-\mathrm{mTOR} / \mathrm{mTOR}$ calculated after quantification of p-mTOR and mTOR by Quantity One v4.62 software in WERI-RB1 cells under normoxic conditions, hypoxic conditions, hypoxic conditions + miR-320 inhibitor and hypoxic conditions + HIF-1 $\alpha$ siRNA. GAPDH was used as a reference protein. ${ }^{* *} \mathrm{P}<0.01$ vs. $\mathrm{RB}$ cells under normoxic conditions; ${ }^{\#} \mathrm{P}<0.01$ vs. RB cells under hypoxic conditions. LC3, light chain 3; $\mathrm{RB}$, retinoblastoma; HIF-1 $\alpha$, hypoxia inducible factor- $1 \alpha$; , phosphorylated; mTOR; mechanistic target of rapamycin. 


\section{Discussion}

It is well established that miRNAs are able to act as tumor suppressors. Evidence has shown that miRNAs could be suitable biomarkers for tumor prognosis and potential therapeutic targets based on the increasing understanding of their mechanisms of action (6-10). Consistent with a previous study (15), we observed significantly higher expression of miR-320 in RB tissues compared with normal tissues, indicating that miR-320 has a role in RB. As is well known, proliferation and metabolism exhaust intratumoral oxygen, and the hypoxic microenvironment, which is partly controlled by HIF-1 $\alpha$, promotes RB development (18). In a simulated hypoxic cultivation, it was demonstrated that the expression of miR-320 in RB tissues increased remarkably under hypoxic conditions, when compared with those cultured under normoxic conditions. The results suggested an association between miR-320 and HIF-1 $\alpha$ in adjusting $\mathrm{RB}$ progression. Increasing evidence has shown that miRNA interfere with the metastasis and invasion of various types of cancer via the regulation of HIF-1 $\alpha$ (21-24). In this study, a luciferase reporter assay was employed to investigate the effect of miR-320 on HIF-1 $\alpha$. The results demonstrated that HIF-1 $\alpha$ was one of the downstream targets of miR-320. Inhibiting miR-320 decreased the mRNA and protein expression levels of HIF-1 $\alpha$, corroborating the positive regulation of miR-320 on HIF-1 $\alpha$ in patients with RB.

Autophagy is an evolutionarily conserved metabolic process in all eukaryotic cells, initiated from sequestered proteins and intracellular organelles by double-membrane-bounded autophagosomes (25). This tissue-specific process is responsible for generating essential macromolecules by degrading the sequestered biological substances and is believed to sustain homeostasis and survival in hosts (26). A recent study has demonstrated that autophagy was indispensable to the survival of hypoxic cells in three human tumor cell lines (27). However, the roles of autophagy in cancer development are two-fold. On one hand, autophagy suppresses carcinogenic progression by clearing aberrant protein agglomerates and damaged organelles and inhibiting prolonged inflammation in the early stage of cancer development. On the other hand, autophagy drives the growth of tumor cells by conferring resistance to metabolic stress when tumor cells encounter nutrient shortage and are rapid multiplying in the advanced stages of carcinogenesis (28). In the present study, it was demonstrated that downregulated miR-320 and silenced HIF-1 $\alpha$ led to reduced LC3 in a dot-like pattern implying that autophagy in RB tissues was inhibited under hypoxic conditions. These findings suggest that miR-320 may affect the level of autophagy by regulating HIF-1 $\alpha$ in RB.

As autophagy results in increased expression levels of autophagy-related proteins, four autophagy-related proteins (LC3, Beclin 1, p62 and mTOR) were analyzed in the present study to reliably evaluate the effects of miR-320 and HIF-1 $\alpha$ on autophagy in RB tissues (29). LC3 is a specific marker of autophagosomes as it is an integral protein of the autophagosome membrane (30). p62, also known as sequestosome-1, is a membrane-bound protein with multiple functions, including bone remodeling, cell death and survival (31). p62 binds to LC3 and reduced p62 is implicated in the activation of autophagy as it undergoes constant degradation during the autophagy process (28). A high LC3/low p62 dot-like pattern may be associated with active autophagy, while a low LC3/p62 dot-like pattern may infer low basal autophagy (32). Beclin 1 is supposedly involved in the translocation of autophagic proteins to a pre-autophagosomal structure in autophagy and is regarded as an important protein in tumor development (33). mTOR is a serine/threonine protein kinase and a modifier of the balance between autophagy and proliferation (34). mTOR is activated by the phosphorylation of Ser2448 through the phosphatidylinositol 3-kinase/Akt pathway. Aberrantly high p-mTOR, which is the activated form, has been associated with poor prognosis in various types of cancer, including esophageal squamous cell carcinoma (35) and small cell lung cancer (36). Whereas, inhibition of the mTOR pathway (dephosphorylation) may lead to the induction of autophagy in cancer (37). Herein, silenced HIF- $1 \alpha$ reduced LC3 puncta and Beclin 1, promoted the expression of p62 mRNA and protein. Furthermore, inhibition of miR-320 and HIF-1 $\alpha$ resulted in elevated p-mTOR levels. These observations revealed that the levels of miR-320 and HIF-1 $\alpha$ may affect autophagy in RB tissues. In conclusion, we propose that miR-320 may regulate autophagy by targeting HIF-1 $\alpha$ and the related mechanism may be associated with the mTOR pathway in RB development.

\section{References}

1. Dimaras H, Kimani K, Dimba EA, Gronsdahl P, White A, Chan HS and Gallie BL: Retinoblastoma. Lancet 379: 1436-1446, 2012.

2. Kivela T: The epidemiological challenge of the most frequent eye cancer: Retinoblastoma, an issue of birth and death. Br J Ophthalmol 93: 1129-1131, 2009.

3. Broaddus E, Topham A and Singh AD: Incidence of retinoblastoma in the USA: 1975-2004. Br J Ophthalmol 93: 21-23, 2009.

4. Abramson DH, Beaverson K, Sangani P, Vora RA, Lee TC, Hochberg HM, Kirszrot J and Ranjithan M: Screening for retinoblastoma: Presenting signs as prognosticators of patient and ocular survival. Pediatrics 112: 1248-1255, 2003.

5. Shields CL and Shields JA: Retinoblastoma management: Advances in enucleation, intravenous chemoreduction, and intra-arterial chemotherapy. Curr Opin Ophthalmol 21: 203-212, 2010.

6. Yates LA, Norbury CJ and Gilbert RJ: The long and short of microRNA. Cell 153: 516-519, 2013.

7. Shen F, Mo MH, Chen L, An S, Tan X, Fu Y, Rezaei K, Wang Z, Zhang L and Fu SW: MicroRNA-21 down-regulates Rb1 expression by targeting PDCD4 in retinoblastoma. J Cancer 5: 804-812, 2014.

8. Wang J, Wang X, Li Z, Liu H and Teng Y: MicroRNA-183 suppresses retinoblastoma cell growth, invasion and migration by targeting LRP6. FEBS J 281: 1355-1365, 2014.

9. Martin A, Jones A, Bryar PJ, Mets M, Weinstein J, Zhang G and Laurie NA: MicroRNAs-449a and $-449 \mathrm{~b}$ exhibit tumor suppressive effects in retinoblastoma. Biochem Biophys Res Commun 440: 599-603, 2013.

10. Wang J, Wang X, Wu G, Hou D and Hu Q: MiR-365b-3p, down-regulated in retinoblastoma, regulates cell cycle progression and apoptosis of human retinoblastoma cells by targeting PAX6. FEBS Lett 587: 1779-1786, 2013.

11. Vishnubalaji R, Hamam R, Yue S, Al-Obeed O, Kassem M, Liu FF, Aldahmash A and Alajez NM: MicroRNA-320 suppresses colorectal cancer by targeting SOX4, FOXM1, and FOXQ1. Oncotarget 7: 35789-35802, 2016.

12. Lei T, Zhu Y, Jiang C, Wang Y, Fu J, Fan Z and Qin H: MicroRNA-320 was downregulated in non-small cell lung cancer and inhibited cell proliferation, migration and invasion by targeting fatty acid synthase. Mol Med Rep 14: 1255-1262, 2016.

13. Zhang T, Zou P, Wang T, Xiang J, Cheng J, Chen D and Zhou J: Down-regulation of miR-320 associated with cancer progression and cell apoptosis via targeting Mcl-1 in cervical cancer. Tumour Biol 37: 8931-8940, 2016. 
14. Wu YY, Chen YL, Jao YC, Hsieh IS, Chang KC and Hong TM: miR-320 regulates tumor angiogenesis driven by vascular endothelial cells in oral cancer by silencing neuropilin 1 . Angiogenesis 17: 247-260, 2014.

15. Zhao JJ, Yang J, Lin J, Yao N, Zhu Y, Zheng J, Xu J, Cheng JQ, Lin JY and Ma X: Identification of miRNAs associated with tumorigenesis of retinoblastoma by miRNA microarray analysis. Childs Nerv Syst 25: 13-20, 2009.

16. Tredan O, Galmarini CM, Patel K and Tannock IF: Drug resistance and the solid tumor microenvironment. J Natl Cancer Inst 99: 1441-1454, 2007.

17. Hu Y, Liu J and Huang H: Recent agents targeting HIF-1 $\alpha$ for cancer therapy. J Cell Biochem 114: 498-509, 2013.

18. Sudhakar J, Venkatesan N, Lakshmanan S, Khetan V, Krishnakumar S and Biswas J: Hypoxic tumor microenvironment in advanced retinoblastoma. Pediatr Blood Cancer 60: $1598-1601,2013$

19. Fernandes BF, Coates J, Odashiro AN, Quezada C, Huynh A, Odashiro PR, Odashiro M and Burnier MN Jr: Hypoxia-inducible factor-1 $\alpha$ and its role in the proliferation of retinoblastoma cells Pathol Oncol Res 20: 557-563, 2014.

20. Livak KJ and Schmittgen TD: Analysis of relative gene expression data using real-time quantitative PCR and the 2(-Delta Delta C(T)) method. Methods 25: 402-408, 2001.

21. Chen Y, Cao KE, Wang S, Chen J, He B, He GU, Chen Y, Peng B and Zhou J: MicroRNA-138 suppresses proliferation, invasion and glycolysis in malignant melanoma cells by targeting HIF-1 $\alpha$. Exp Ther Med 11: 2513-2518, 2016.

22. Yang X, Lei S, Long J, Liu X and Wu Q: MicroRNA-199a-5p inhibits tumor proliferation in melanoma by mediating HIF-1 $\alpha$. Mol Med Rep 13: 5241-5247, 2016.

23. Ge X, Liu X, Lin F, Li P, Liu K, Geng R, Dai C, Lin Y, Tang W, $\mathrm{Wu} \mathrm{Z}$ and Chang J: MicroRNA-421 regulated by HIF-1 $\alpha$ promotes metastasis, inhibits apoptosis, and induces cisplatin resistance by targeting E-cadherin and caspase-3 in gastric cancer. Oncotarget 7: 24466-24482, 2016.

24. Chang RM, Xu JF, Fang F, Yang H and Yang LY: MicroRNA-130b promotes proliferation and EMT-induced metastasis via PTEN/p-AKT/HIF-1 $\alpha$ signaling. Tumour Biol 37: 10609-10619, 2016.

25. Kondo Y, Kanzawa T, Sawaya R and Kondo S: The role of autophagy in cancer development and response to therapy. Nat Rev Cancer 5: 726-734, 2005.
26. White E: The role for autophagy in cancer. J Clin Invest 125 42-46, 2015.

27. Tan Q, Wang M, Yu M, Zhang J, Bristow RG, Hill RP and Tannock IF: Role of autophagy as a survival mechanism for hypoxic cells in tumors. Neoplasia 18: 347-355, 2016.

28. Honscheid P, Datta K and Muders MH: Autophagy: Detection, regulation and its role in cancer and therapy response. Int $\mathrm{J}$ Radiat Biol 90: 628-635, 2014.

29. Schläfli AM, Adams O, Galván JA, Gugger M, Savic S, Bubendorf L, Schmid RA, Becker KF, Tschan MP, Langer R and Berezowska S: Prognostic value of the autophagy markers LC3 and p62/SQSTM1 in early-stage non-small cell lung cancer. Oncotarget 7: 39544-39555, 2016.

30. Kabeya Y, Mizushima N, Ueno T, Yamamoto A, Kirisako T, Noda T, Kominami E, Ohsumi Y and Yoshimori T: LC3, a mammalian homologue of yeast Apg8p, is localized in autophagosome membranes after processing. EMBO J 19: 5720-5728, 2000 .

31. Moscat J and Diaz-Meco MT: p62 at the crossroads of autophagy, apoptosis, and cancer. Cell 137: 1001-1004, 2009.

32. Liu JL, Chen FF, Lung J, Lo CH, Lee FH, Lu YC and Hung CH: Prognostic significance of p62/SQSTM1 subcellular localization and LC3B in oral squamous cell carcinoma. Br J Cancer 111: 944-954, 2014

33. Kang R, Zeh HJ, Lotze MT and Tang D: The Beclin 1 network regulates autophagy and apoptosis. Cell Death Differ 18: 571-580, 2011.

34. Jung $\mathrm{CH}$, Ro SH, Cao J, Otto NM and Kim DH: mTOR regulation of autophagy. FEBS Lett 584: 1287-1295, 2010.

35. Hirashima K, Baba Y, Watanabe M, Karashima R, Sato N, Imamura Y, Hiyoshi Y, Nagai Y, Hayashi N, Iyama K and Baba H: Phosphorylated mTOR expression is associated with poor prognosis for patients with esophageal squamous cell carcinoma. Ann Surg Oncol 17: 2486-2493, 2010.

36. Lee JH, Kang KW and Lee HW: Expression of phosphorylated mTOR and its clinical significances in small cell lung cancer. Int J Clin Exp Pathol 8: 2987-2993, 2015.

37. Gong G, Hu L, Liu Y, Bai S, Dai X, Yin L, Sun Y, Wang X and Hou L: Upregulation of HIF-1 $\alpha$ protein induces mitochondrial autophagy in primary cortical cell cultures through the inhibition of the mTOR pathway. Int J Mol Med 34: 1133-1140, 2014. 